\title{
Síntese, assinalamento completo e estudo do perfil farmacocinético, bioativo e de toxicidade do 2-propin-1-il 2,3,4,6-tetra- $O$-acetil- $\beta$-D-glicopiranose
}

Synthesis, completed assignment and study of the pharmacokinetic, bioactive and toxicity profile of 2-propyn-1-yl 2,3,4,6-tetra- $O$-acetyl- $\beta$-D-glycopyranose

\author{
J. A. M. Santos ${ }^{1,2 *}$; C. L. A. A. Santos ${ }^{3}$; J. R. Freitas Filho ${ }^{1}$; J. C. R. Freitas ${ }^{1,4}$ \\ ${ }^{1}$ Departamento de Química, Univesidade Federal Rural de Pernambuco, 52171-900, Recife-PE, Brasil \\ ${ }^{2}$ Instituto Federal de Educação, Ciências e Tecnologia de Pernambuco, 55560-000, Barreiros-PE, Brasil \\ ${ }^{3}$ Departamento de Química Fundamental, Universidade Federal de Pernambuco, 50670-901, Recife-PE, Brasil. \\ ${ }^{4}$ Centro de Educação e Saúde, Universidade Federal de Campina Grande, 58175-000, Cuité-PB, Brasil \\ *jonh_quimica@yahoo.com \\ (Recebido em 08 de maio de 2020; aceito em 20 de julho de 2020)
}

\begin{abstract}
Os $O$-glicosídeos são carboidratos de ocorrência natural e que apresentam atividades biológicas promissoras. No entanto, o caminho convencional para comercialização de um medicamento envolve um processo exaustivo e caro. Em contrapartida, pesquisas baseadas em uma abordagem in silico, têm se mostrado eficientes na predição de propriedades farmacodinâmicas, reduzindo tempo e custos. Nesse trabalho, relatamos a síntese, assinalamento completo e avaliação do perfil farmacocinético e de toxicidade do 2propin-1-il 2,3,4,6-tetra- $O$-acetil- $\beta$-D-glicopiranose. O composto foi obtido em bom rendimento e excelente estereosseletividade. A partir do experimento de NOESY foi possível determinar o produto majoritário da reação de glicosilação. O estudo in silico, relatado pela primeira vez, indicou que este composto apresenta boa biodisponibilidade oral, é ativo frente aos principais alvos moleculares e exibe baixa toxicidade.

Palavras-chave: In silico, $O$-glicosídeos, Assinalamento completo.
\end{abstract}

$O$-glycosides are naturally occurring carbohydrates that have promising biological activities. However, the conventional way to market a drug involves an exhaustive and expensive process. On the other hand, research based on in silico approach has been shown to be efficient in predicting pharmacodynamic properties, reducing time and costs. In this work, we report the synthesis, complete labeling and evaluation of the pharmacokinetic and toxicity profile of 2-propyn-1-yl 2,3,4,6-tetra- $O$-acetyl- $\beta$-D-glycopyranose. The compound was obtained in good yield and excellent stereoselectivity. From the NOESY experiment it was possible to determine the major product of the glycosylation reaction. The in silico study, reported for the first time, indicated that this compound has good oral bioavailability, is active against the main molecular targets and exhibits low toxicity.

Keywords: In silico, $O$-glycosides, Completed assignment.

\section{INTRODUÇÃO}

O desenvolvimento de novos medicamentos é um processo muito complexo, que inclui a seleção da doença, identificação de alvos biológicos, descoberta e otimização de "lead compound" (molécula com atividade farmacológica promissora que necessita de melhoramento), além de ensaios pré-clínicos e clínicos $[1,2,3,4]$. Na última década, inúmeros candidatos a fármacos foram descartados em testes clínicos devido a duas principais causas, a citar, falta de eficácia e alta toxicidade [5, 6, 7]. Nesse contexto, a abordagem tradicional é desafiadora, cara e envolve muitos aspectos que tem impacto negativo na indústria farmacêutica $[8,9,10]$. Em contraponto, o uso de métodos computacionais, denominado in silico, podem acelerar o design de medicamentos e vêm sendo amplamente empregado na química medicinal [11,12,13]. A abordagem in sílico auxilia na descoberta de novos agentes terapêuticos de forma eficiente, visto que, o alvo biológico, e, portanto, a atividade biológica pode ser prevista no estágio inicial do processo $[14,15,16]$.

$\mathrm{O}$ avanço na química de carboidratos, nos últimos anos, possibilitou a descoberta, síntese e modificações estruturais de glicosídeos, fornecendo moléculas com diversas aplicações medicinais. Dentre as inúmeras atividades biológicas dos glicosídeos, destacam-se: antiprotozoário [17] 
antiglicêmico [18], antibacteriano [19], anti-inflamatório [20], antiviral [21] e antitumoral [22], entre outras [23, 24, 25, 26] (Figura 1).

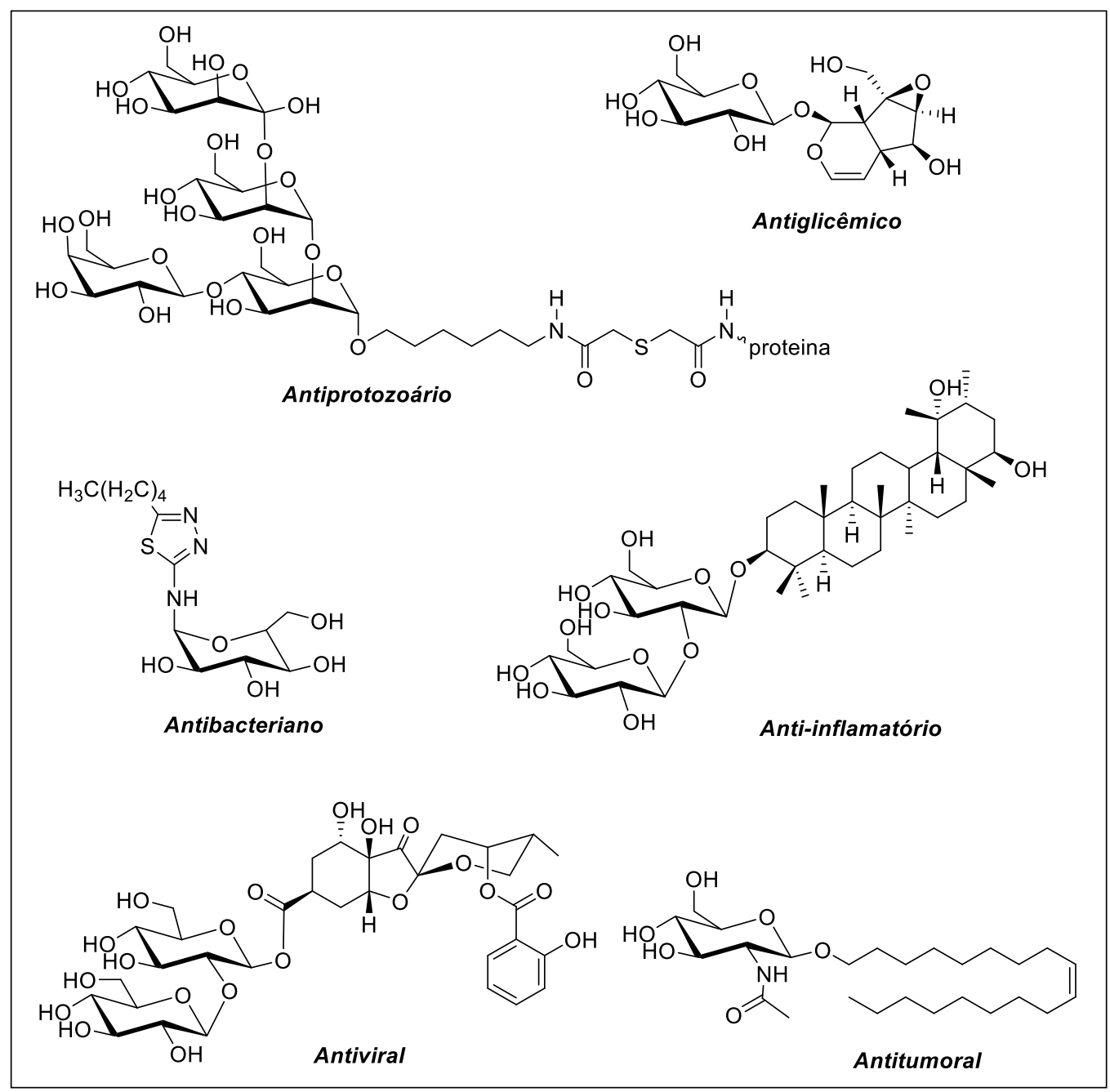

Figura 1: Exemplos de glicosídeos naturais e sintéticos bioativos.

Adicionalmente, o conhecimento da estrutura versus atividade biológica é essencial no desenvolvimento de novos medicamentos, uma vez que a interação do fármaco com o receptor biológico envolve ligações seletivas que são intimamente dependentes as suas características estruturais $[27,28]$. No entanto, o assinalamento inequívoco de compostos com elevada complexidade estrutural, a citar os $O$-glicosídeos, é um desafio.

Nesse sentido, a ressonância magnética nuclear (RMN) destaca-se como a principal técnica espectroscópica aplicada na elucidação estrutural de compostos orgânicos [29, 30]. Os aparelhos de RMN mais modernos utilizam o método pulsado, no qual, os núcleos são submetidos a um campo magnético e por meio de pulsos de radiação de radiofrequência, são excitados. Quando estes núcleos voltam ao estado fundamental irradiam energia. A soma da energia irradiada por todos os núcleos é então somada, gerando o decaimento de indução livre (FID, do inglês Free Induction Decay) [31].

Diante do exposto, o objetivo do trabalho foi realizar o assinalamento completo e a determinação da estereoquímica do carbono anomérico do 2-propin-1-il 2,3,4,6-tetra- $O$-acetil- $\beta$-D-glicopiranose, utilizado as técnicas unidimensionais (Infravermelho, RMN), bem como, as técnicas bidimensionais COSY (Espectroscopia de Correlação Homonuclear), HSQC (Correlação Heteronuclear de um Único Quantum), HMBC (Correlação Heteronuclear de Múltiplas Ligações) e NOESY (Espectroscopia de Efeito Nuclear Overhauser). Adicionalmente, foi realizado uma avaliação teórica do perfil farmacocinético e de toxicidade do 2-propin-1-il 2,3,4,6-tetra- $O$-acetil$\beta$-D-glicopiranose a partir do método in silico. 


\section{MATERIAL E MÉTODOS}

\subsection{Materiais}

Os solventes foram adquiridos na sua forma comercial, P.A., dos fornecedores Merck, Aldrich, Vetec e Cinética. O hexano e o acetato de etila foram purificados conforme protocolo descrito na literatura [32], através da destilação empregando coluna de Vigreux. O diclorometano foi destilado sob hidreto de cálcio e mantido sob cloreto de cálcio. Os reagentes 1,2,3,4,6-penta- $O$-acetil- $\beta$-Dglicopiranose e 2-propin-1-ol foram obtidos comercialmente da empresa Sigma Aldrich. O acompanhamento da reação foi realizado através de cromatografia em camada delgada (CCD), onde foi utilizado placas prontas de sílica-gel contendo indicador fluorescente $\mathrm{F}_{254}$ da Merck. Para revelação dos compostos foi utilizado solução etanólica ácida $\left[\left(\mathrm{EtOH} / \mathrm{H}_{2} \mathrm{SO}_{4}\right)(9,5: 0,5 ; \mathrm{v}: \mathrm{v})\right]$ sob aquecimento. Para cromatografia em coluna foi utilizado sílica-gel 60 (Merck, 70-230 mesh) como fase estacionaria e sistemas Hexano/Acetato de etila como fase fluida.

\subsection{Equipamentos}

A chapa de agitação com aquecimento e a manta aquecedora foram da marca Fisaton modelo 754A e 102E, respectivamente. O solvente foi removido utilizando um evaporador rotativo da Büchi modelo R-114 conectado a uma bomba de vácuo modelo KNF-Neuberger, e o solvente remanescente foi removido utilizando uma bomba de alto vácuo da Edwards modelo RV3. A rotação específica foi determinada em um polarímetro digital da marca JASCO ${ }^{\circledR} \mathrm{P}-2000$ equipado com a luz de sódio em comprimento de onda $589 \mathrm{~nm}$. A amostra foi preparada em concentração de $1 \mathrm{~g} / \mathrm{mL}$ (em MeOH) em uma cubeta de $1 \mathrm{~mL}$.

Os espectros de ressonância magnética nuclear foram registrados em um espectrômetro Varian URMNS de $400 \mathrm{MHz}$. Os deslocamentos químicos estão expressos em ppm (partes por milhão) em relação ao pico residual do clorofórmio $(7,258 \mathrm{ppm})$ para os espectros de hidrogênio, em relação ao pico central do $\mathrm{CDCl}_{3}(77,0 \mathrm{ppm})$ para os espectros de carbono. Todas as constantes de acoplamento $(J)$ foram descritas em hertz $(\mathrm{Hz})$. Os espectros no infravermelho foram registrados em um em espectrofotômetro de infravermelho (IV) com transformada de Fourier no instrumento Bruker Modelo IFS66, sendo a amostra preparadas como pastilhas de $\mathrm{KBr}$.

\subsection{Medições de RMN}

Para as medições, a concentração da amostra foi mantida em $20 \mathrm{mg} / \mathrm{mL}$ em $\mathrm{CDCl}_{3}$ com TMS a $0,03 \%$. A temperatura da amostra foi de $300 \mathrm{~K}$. O espectro RMN ${ }^{1} \mathrm{H}$ foi adquirido com largura espectral igual a $5,48 \mathrm{kHz}, 64 \mathrm{k}$ pontos de dados e 16 varreduras - fornecendo resolução digital de $0,083 \mathrm{~Hz}$ (largura do pulso de ${ }^{1} \mathrm{H} 30^{\circ}=8,5 \mu \mathrm{s}$ ). Para o espectro $\mathrm{RMN}{ }^{13} \mathrm{C}$ foi adquirido com largura espectral igual a $23,98 \mathrm{kHz}, 32 \mathrm{k}$ pontos de dados e 1024 varreduras - fornecendo resolução digital de $0,732 \mathrm{~Hz}\left({ }^{13} \mathrm{C}\right.$ largura de pulso de $30^{\circ}=14,25 \mu$ s). As correlações de deslocamento químico $2 \mathrm{D}$ foram realizadas usando sequências de pulsos padrão fornecidas pelo fabricante do espectrômetro.

As correlações de desvio químico de ${ }^{13} \mathrm{C} /{ }^{1} \mathrm{H}$ de longo alcance foram obtidas em experimentos com valores de atraso otimizados para ${ }^{2} J(\mathrm{C}, \mathrm{H})=8 \mathrm{~Hz}$.

\subsection{Síntese do 2-propin-1-il 2,3,4,6-tetra- $O$-acetil- $\beta$-D-glicopiranose}

O 2-propin-1-il 2,3,4,6-tetra- $O$-acetil- $\beta$-D-glicopiranose foi obtido de acordo com o procedimento relatado por Mereyala e Gurrala (1998) [33]. Dessa forma, em um balão foi preparado uma solução de 1,2,3,4,6-penta- $O$-acetil- $\beta$-D-glicopiranose $(\mathbf{1}, 1,17 \mathrm{~g}, 3,0 \mathrm{mmol}) \mathrm{com}$ o 2-propin-1-ol (2, 0,26 mL, 0,252 g, 4,5 mmol) em $15 \mathrm{~mL}$ de diclorometano. A mistura foi resfriada a $0{ }^{\circ} \mathrm{C}$ e mantida sob atmosfera de argônio. Na sequência foi adicionado o $\mathrm{BF}_{3} \bullet\left(\mathrm{OCH}_{3}\right)_{2}(0,21 \mathrm{~mL}$, $0,256 \mathrm{~g}, 2,25 \mathrm{mmol}$ ) e o banho de gelo foi removido. A formação do 2-propin-1-il 2,3,4,6-tetra- $O$ acetil- $\beta$-D-glicopiranose (3) foi acompanhada por cromatografia de camada delgada (CCD). Após o termino da reação a mistura reacional foi lavada três vezes com uma solução saturada de $\mathrm{NaHCO}_{3}$ 
e uma vez com $\mathrm{NaCl}$. A fase orgânica foi seca com $\mathrm{NaSO}_{4}$ anidro e o produto foi purificado por cromatografia em coluna empregando um sistema eluente de hexano/acetato de etila (70:30; v:v).

\subsection{Análises in sílico}

\subsubsection{Avaliação de perfil farmacocinético e de bioatividade}

Para avaliar o perfil farmacocinético do 2-propin-1-il 2,3,4,6-tetra- $O$-acetil- $\beta$-D-glicopiranose (3), foi utilizado o software Molinspiration Online Property Calculation. Este software possibilita o cálculo de importantes propriedades físico-químicas da molécula. Estes parâmetros foram utilizados para avaliar o padrão de biodisponibilidade teórica do composto, baseando-se na "Regra dos Cinco" desenvolvida por Lipinski et al. (1997) [34]. O software Molinspiration Online Property Calculation também foi utilizado no cálculo do escore de bioatividade do composto 3 frente aos alvos mais importantes das drogas (ligante GPCR, modulador de canal iônico, inibidor de quinase, ligante de receptor nuclear, inibidor de protease e de enzima).

\subsubsection{Avaliação da toxicidade}

Com o objetivo de identificar qualquer propriedade toxica do 2-propin-1-il 2,3,4,6-tetra- $O$ acetil- $\beta$-D-glicopiranose (3), foi utilizado o software Osiris Property Explorer. A previsão foi baseada na similaridade dos grupos funcionais do composto $\mathbf{3}$ com moléculas validadas in vitro e in vivo presentes banco de dados do programa. Foram calculadas algumas propriedades tóxicas, como efeitos mutagênicos, tumorogênicos, irritantes e reprodutivos.

\section{RESULTADOS E DISCUSSÃO}

A síntese visando o assinalamento completo do 2-propin-1-il 2,3,4,6-tetra- $O$-acetil- $\beta$-Dglicopiranose (3) foi realizada de acordo com o protocolo de Mereyala e Gurrala (1998) [33]. Assim, a reação de glicosilação entre o 1,2,3,4,6-penta- $O$-acetil- $\beta$-D-glicopiranose (1) e o 2-propin1-ol (2) catalisada por $\mathrm{BF}_{3} \bullet\left(\mathrm{OCH}_{3}\right)_{2}$ levou ao glicosídeo $3 \mathrm{em} 4,0 \mathrm{~h}$ e em um bom rendimento (87\%) (Figura 2). Dentre as metodologias descritas na literatura para reação de glicosilação [35, 36, 37], este método foi escolhido devido a sua eficiência e tolerância a diferentes grupos funcionais.

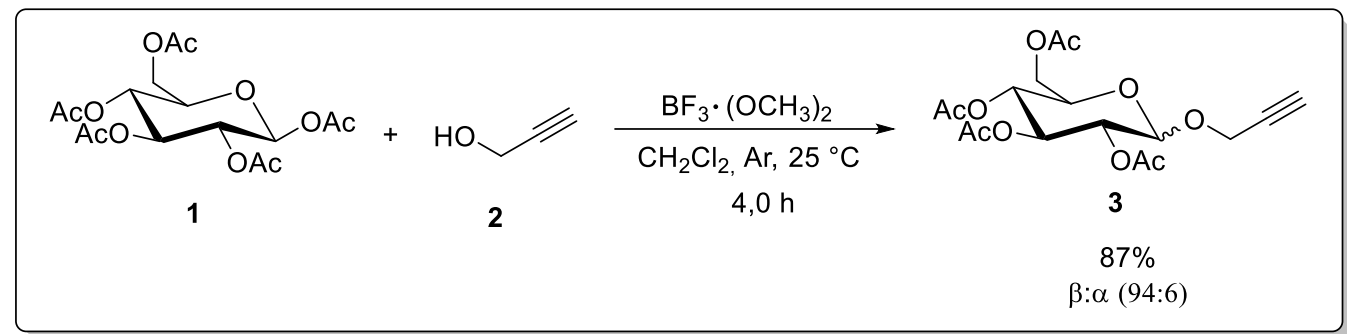

Figura 2. Síntese do composto 3 via a reação de glicosilação.

A partir da análise da mistura reacional, através de cromatografia gasosa, foi observado uma razão diastereomérica (r.d.) de 94:6 que demonstra a excelente estereosseletividade da reação (Figura 3). Após purificação, o produto majoritário foi obtido na forma de um sólido branco amorfo com ponto de fusão de $109-110^{\circ} \mathrm{C}$ e rotação especifica $[\alpha]_{\mathrm{D}}{ }^{25}-29,7$ (c $2,07 \mathrm{mg} / \mathrm{mL} ; \mathrm{CHCl}_{3}$ ), os quais corroboram com os dados da literatura [33, 38, 39]. 


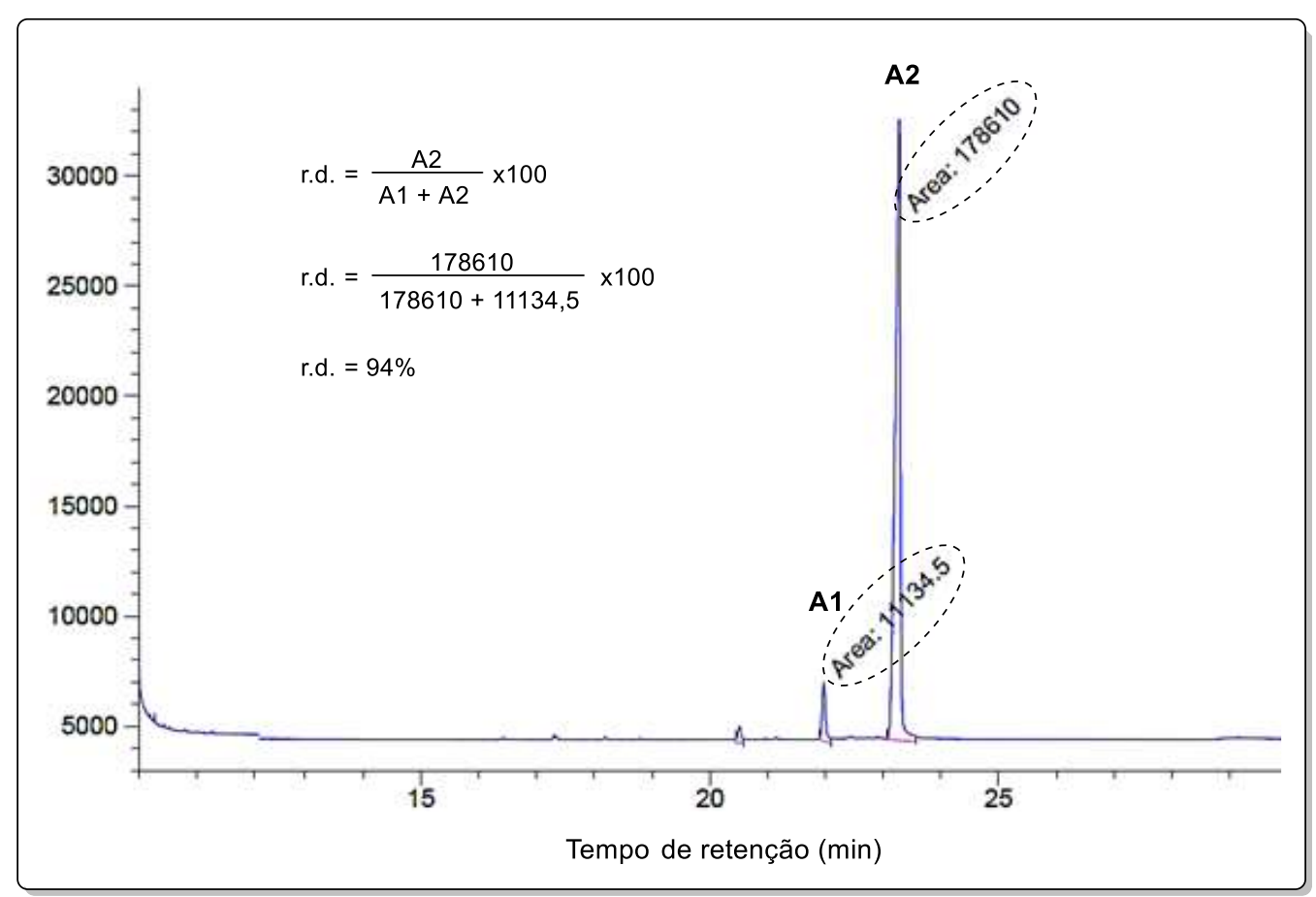

Figura 3. Determinação da razão diastereomérica dos anômeros.

Levando em consideração os principais fatores que controlam a estereosseletividade da glicosilação de Fischer [40], a citar, as interações 1,3-diaxiais e assistência anquimérica, o produto majoritário dessa reação é o anômero $\beta$. Dessa forma, a confirmação do anômero majoritário e o assinalamento completo dos núcleos de $\mathrm{H}$ e $\mathrm{C}$ foi realizado empregando diferentes técnicas espectroscópicas, tais como, IV e RMN (1D e 2D).

No espectro de infravermelho foram identificadas as bandas característica do composto 3 que incluem as deformações em 3275, 2970, 2120, 1734, $1039 \mathrm{~cm}^{-1}$, referentes aos estiramentos das ligações $\mathrm{C} \equiv \mathrm{C}, \mathrm{C}-\mathrm{H}, \mathrm{C} \equiv \mathrm{C}-\mathrm{H}, \mathrm{C}=\mathrm{O}$ e $\mathrm{C}-\mathrm{O}$, respectivamente. As vibrações em 3275 e $2120 \mathrm{~cm}^{-1}$, que indicam a presença da ligação tripla, comprovam a conversão do material de partida no glicosídeo acetilênico (Figura 4).

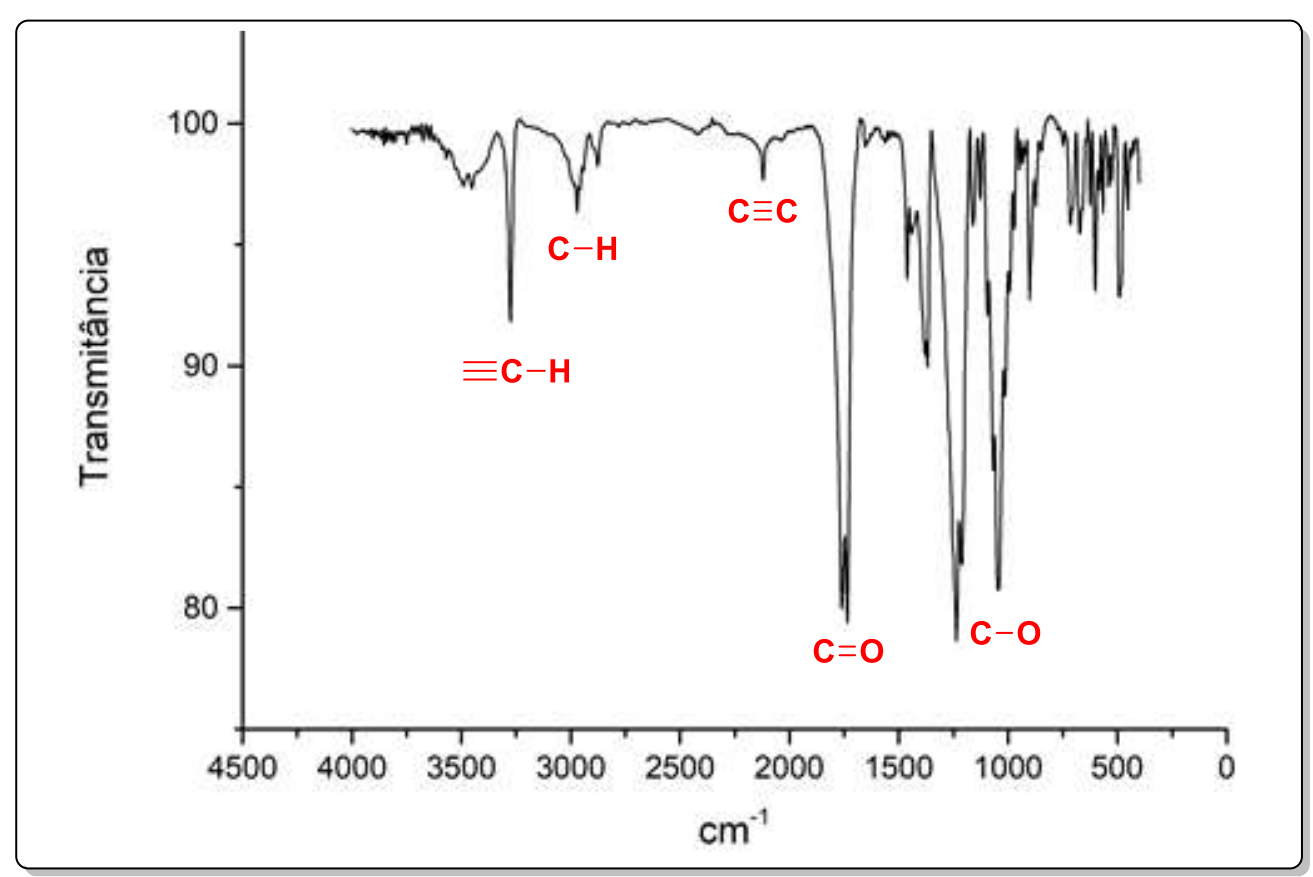

Figura 4. Espectro de IV (pastilha de $\mathrm{KBr}$ ) do composto 3. 
Analisando o espectro de RMN ${ }^{1} \mathrm{H}$ (Figura 5), verifica-se a presença dos 22 hidrogênios da molécula, dos quais, 12 são referentes aos hidrogênios das metilas dos grupos OAc. Esses sinais podem ser encontrados na região entre $\delta_{H}$ 2,07-1,99 ppm como quatro simpletos. Com o auxílio da técnica COSY foi realizada as atribuições dos demais sinais do espectro de RMN ${ }^{1} \mathrm{H}$. Os detalhes são apresentados a seguir.

I. A aglicona $\left(-\mathrm{CH}_{2}-\mathrm{C} \equiv \mathrm{C}-\mathrm{H}\right)$ origina um sinal em $\delta_{H} 2,47 \mathrm{ppm}\left({ }^{4} J_{H 9-H 7}=2,4 \mathrm{~Hz}\right)$, atribuído ao hidrogênio acetilênico (H9), uma vez que o H9 sofre efeito anisotrópico de blindagem da ligação tripla [41] e apresenta multiplicidade do tipo tripleto devido ao acoplamento a quatro ligações com os hidrogênios metileno (H7), o qual origina um dupleto em $\delta_{H} 4,36$ ppm $\left({ }^{4} J_{H 7-H 9}=2,8 \mathrm{~Hz}\right)$. Acoplamentos de longo alcance que ocorrem normalmente em sistemas aromáticos, alilicos e propargilicos, exibem baixos valores de constantes de acoplamento. Nos acoplamentos propargílicos, os valores de $J$ variam de 2 a $4 \mathrm{~Hz}$ [42]. Esses sinais reforçam a incorporação do grupamento 2-propin-1-il.

II. O sinal em $\delta_{H} 4,77 \mathrm{ppm}$ foi atribuído ao hidrogênio anomérico (H1), uma vez que o H1 apresenta multiplicidade do tipo dupleto $\left({ }^{3} J_{\mathrm{Hl}-\mathrm{H} 2}=7,6 \mathrm{~Hz}\right)$ devido o acoplamento com $\mathrm{H} 2$. O hidrogênio $\mathrm{H} 2$ acopla com $\mathrm{H} 1$ e $\mathrm{H} 3$ gerando um sinal com multiplicidade do tipo dupleto de dupleto em $\delta_{H} 5,00 \mathrm{ppm}\left({ }^{3} J_{H 2-H 3}=10,0 \mathrm{~Hz},{ }^{3} J_{H 2-H 1}=7,6 \mathrm{~Hz}\right)$. A constante de acoplamento de menor valor $\left({ }^{3} J=7,6 \mathrm{~Hz}\right)$, igual a de $\mathrm{H} 1$, corrobora a atribuição

III. O hidrogênio H3, apresenta multiplicidade do tipo dupleto de dupleto, pode ser observado em $\delta_{H} 5,23 \mathrm{ppm}\left({ }^{3} J_{H 3-H 2}=9,6 \mathrm{~Hz},{ }^{3} J_{H 3-H 4}=9,2 \mathrm{~Hz}\right)$.

IV. O sinal em $\delta_{H} 5,09$ ppm foi atribuído ao hidrogênio H4, o qual acopla com os hidrogênios vizinhos, $\mathrm{H} 3 \mathrm{e}$ e $\mathrm{H} 5$, gerando uma multiplicidade do tipo dupleto de dupleto com constantes de acoplamento de ${ }^{3} J_{H 4-H 5}=10,0 \mathrm{~Hz} \mathrm{e}^{3} J_{H 4-H 3}=9,2 \mathrm{~Hz}$.

V. Em $\delta_{H} 3,72 \mathrm{ppm}$ foi possível verificar a presença de um sinal com multiplicidade do tipo dupleto de dupleto de dupleto atribuído ao hidrogênio H5 que acopla com os hidrogênios H4 e os prótons diastereotópicos H6 e H6', implicando em três constantes de acoplamento $\left({ }^{3} J_{H 5-H 4}=10 \mathrm{~Hz} ;{ }^{3} J_{H 5-H 6}=4,8 \mathrm{~Hz} ;{ }^{3} J_{H 5-H 6^{\prime}}=2,4 \mathrm{~Hz}\right)$.

VI. Os hidrogênios, $\mathrm{H6}\left({ }^{2} J_{H 6-H 6^{\prime}}=12,4 \mathrm{~Hz} ;{ }^{3} J_{H 6-H 5}=4,8 \mathrm{~Hz}\right)$ e H6 $\left({ }^{2} J_{H 6^{\prime}-H 6}=12,4 \mathrm{~Hz} ;{ }^{3} J_{H 6^{\prime}-H 5}\right.$ $=2,4 \mathrm{~Hz}$ ), geram dois sinais com multiplicidade dupleto de dupleto em $\delta_{H} 4,27 \mathrm{ppm}$ e $\delta_{H}$ 4,14 ppm. Essa multiplicidade é observada uma vez que cada próton acopla com o vizinho H5 e devido o acoplamento geminal entre eles. O acoplamento a duas ligações é responsável pela maior constante de acoplamento. 


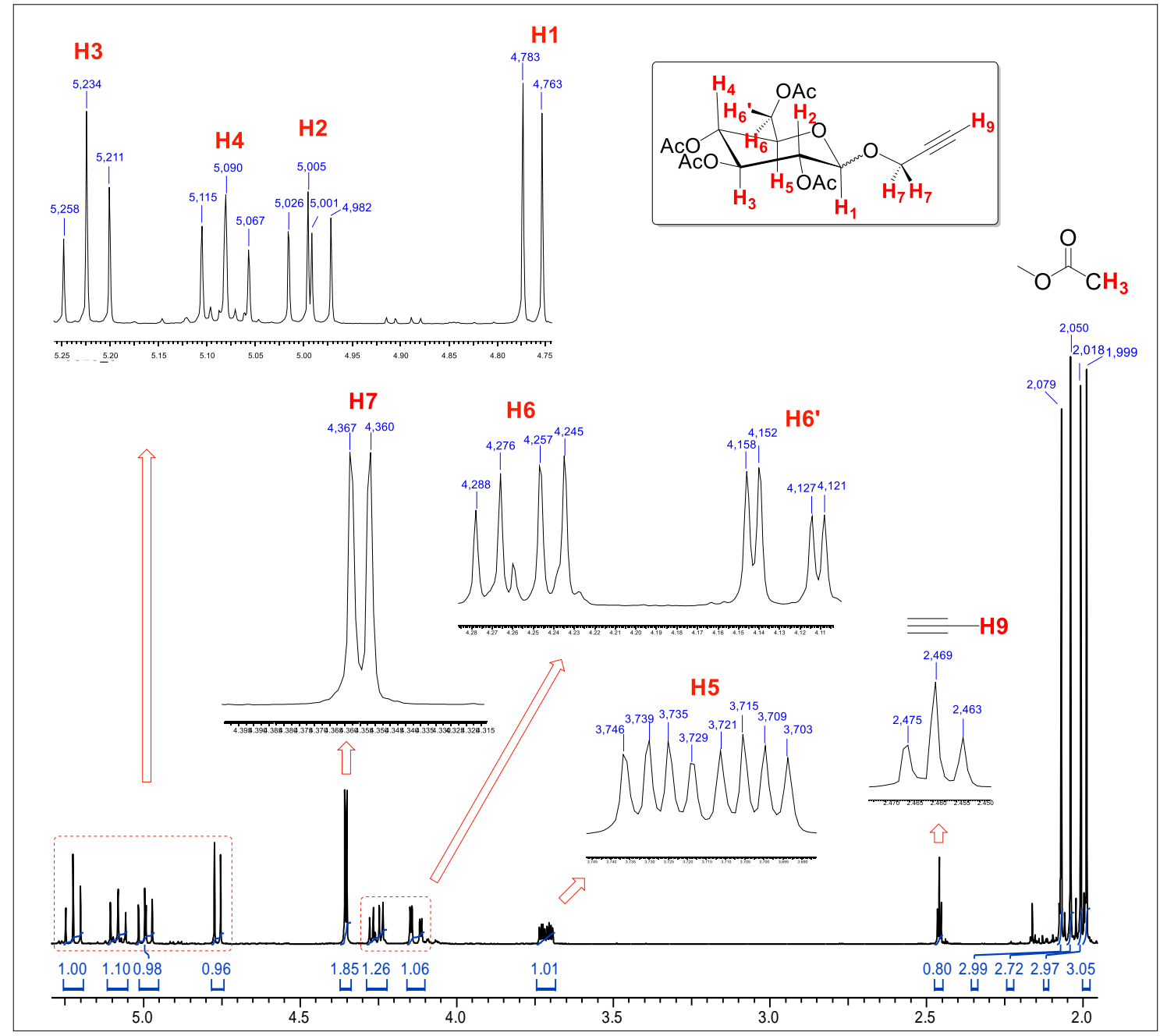

Figura 5. Espectro de $\mathrm{RMN}^{1} \mathrm{H}\left(\mathrm{CDCl}_{3}, 400 \mathrm{MHz}\right)$ do composto 3 .

No espectro de carbono foi possível verificar a presença de 17 sinais que correspondem exatamente ao número de carbonos quimicamente diferente no composto 3. Esses sinais ocorrem em três regiões no espectro: quatros picos em campo baixo na região entre $\delta_{C} 169,3$ a 170,6 ppm que são referentes aos carbonos carbonílicos dos grupos OAc, quatros picos em campo alto que são originados pelas metilas dos grupos OAc e nove picos, que podem ser vistos na região entre $\delta_{C} 55,9$ a 98,1 ppm, referentes aos demais átomos de carbono do composto 3 (Figura 6).

A atribuição dos átomos de carbonos C1, C2, C3, C4, C5, C6 e C7 foi realizado utilizando um experimento de correlação heteronuclear de um único quantum (HSQC) entre os núcleos de ${ }^{1} \mathrm{H}$ e ${ }^{13} \mathrm{C}$, no qual é possível observar a correlação entre átomos de carbono e hidrogênio a uma ligação de distância (Figura 7). 


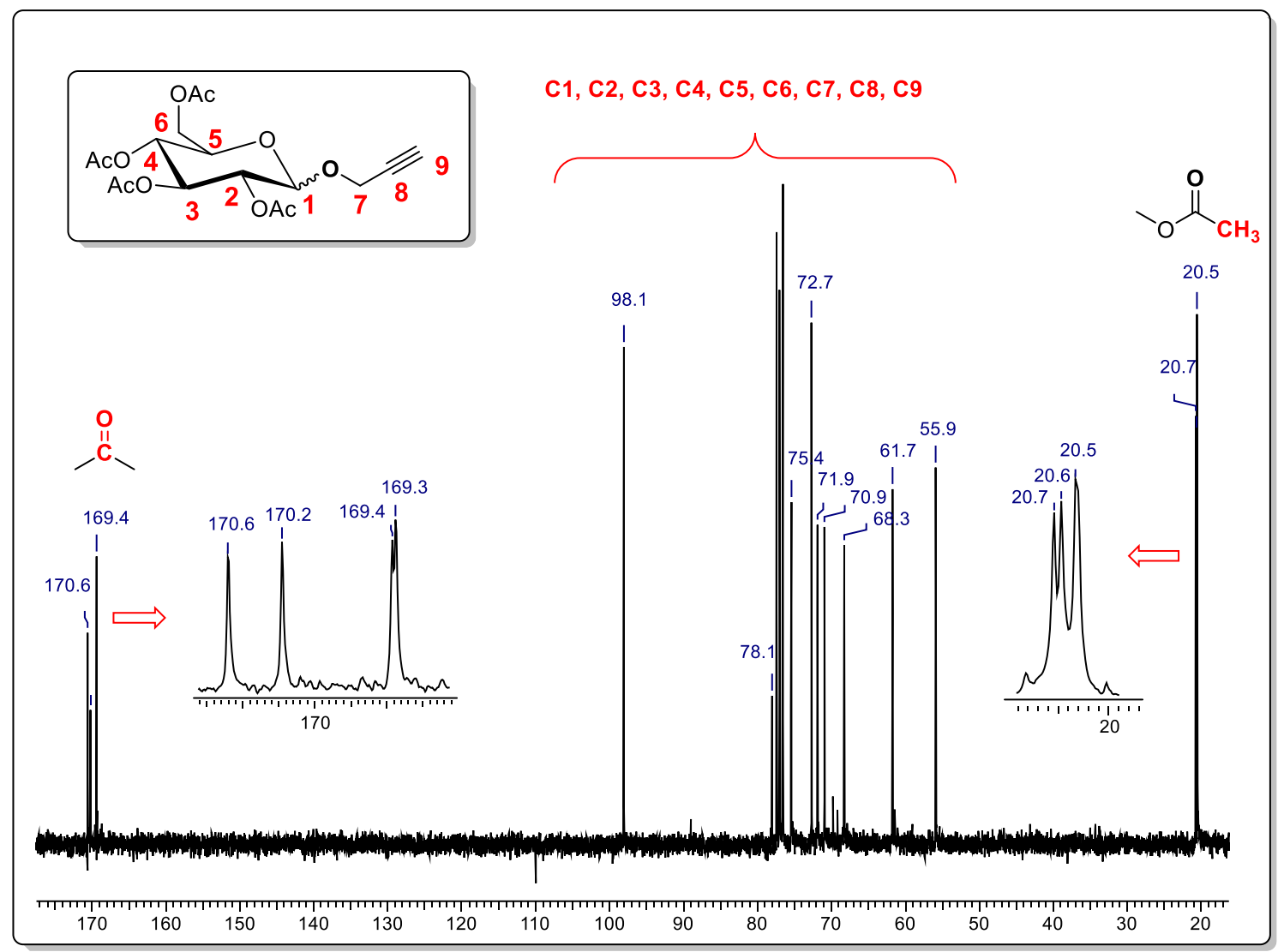

Figura 6: Espectro de $\mathrm{RMN}^{13} \mathrm{C}\left(\mathrm{CDCl}_{3}, 100 \mathrm{MHz}\right)$ do composto 3.

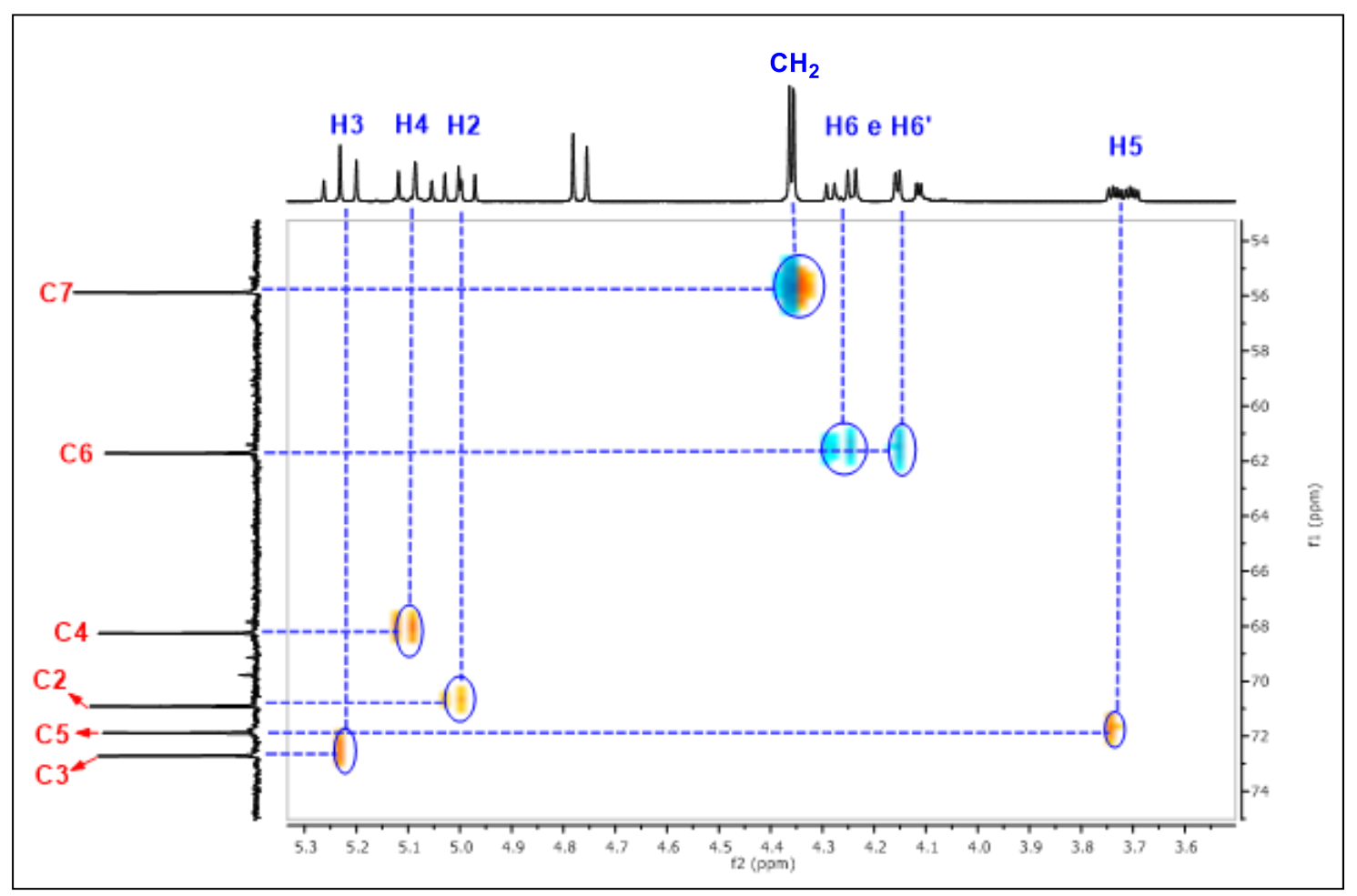

Figura 7: Espectro de $\mathrm{HSQC}{ }^{1} \mathrm{H}-^{13} \mathrm{C}$ do composto 3.

Avaliando o espectro HSQC (Figura 7), nota-se que o sinal em $\delta_{C} 72,7 \mathrm{ppm}$ corresponde ao C3, uma vez que exibe correlação com o sinal em $\delta_{H} 5,23$ ppm referente ao H3. O sinal em $\delta_{C} 71,9$ ppm 
correlaciona-se com H5 ( $\delta_{H} 3,72 \mathrm{ppm}$ ), e dessa forma, foi atribuído ao C5, enquanto o sinal em $\delta_{C}$ $70,9 \mathrm{ppm}$ foi atribuído ao $\mathrm{C} 2$, pois correlaciona-se com o sinal de $\mathrm{H} 2\left(\delta_{H} 5,00 \mathrm{ppm}\right)$. Para o C4 foi atribuído o sinal em $\delta_{C} 68,3 \mathrm{ppm}$ devido o cruzamento com $\mathrm{H} 4$ ( $\delta_{H} 5,09 \mathrm{ppm}$ ). Os hidrogênios diastereotópicos H6 e H6' apresentam correlação com o pico em $\delta_{C} 61,7$ ppm, logo este sinal foi atribuído ao C6. Adicionalmente, o carbono C7 corresponde ao sinal em $\delta_{C} 55,9 \mathrm{ppm}$ devido sua correlação com os hidrogênios metileno $\mathrm{H} 7\left(\delta_{H} 4,36 \mathrm{ppm}\right)$. O sinal de $\mathrm{C} 7$ em campo alto é causado pela anisotropia diamagnética gerada pelos elétrons $\pi$ do grupo acetileno [41].

Dentre os carbonos de hibridização $s p^{3}$, o carbono anomérico $\mathrm{C} 1$ é o mais desblindado devido sua proximidade aos dois átomos de oxigênio que retiram densidade eletrônica por indução. Adicionalmente, isto é reforçado pela análise do espectro de HSQC dessa região, o qual é possível observar a correlação entre o sinal em $\delta_{C} 98,1 \mathrm{ppm}$ com o sinal em $\delta_{H} 4,77$ ppm referente a $\mathrm{H} 1$ (Figura 8).

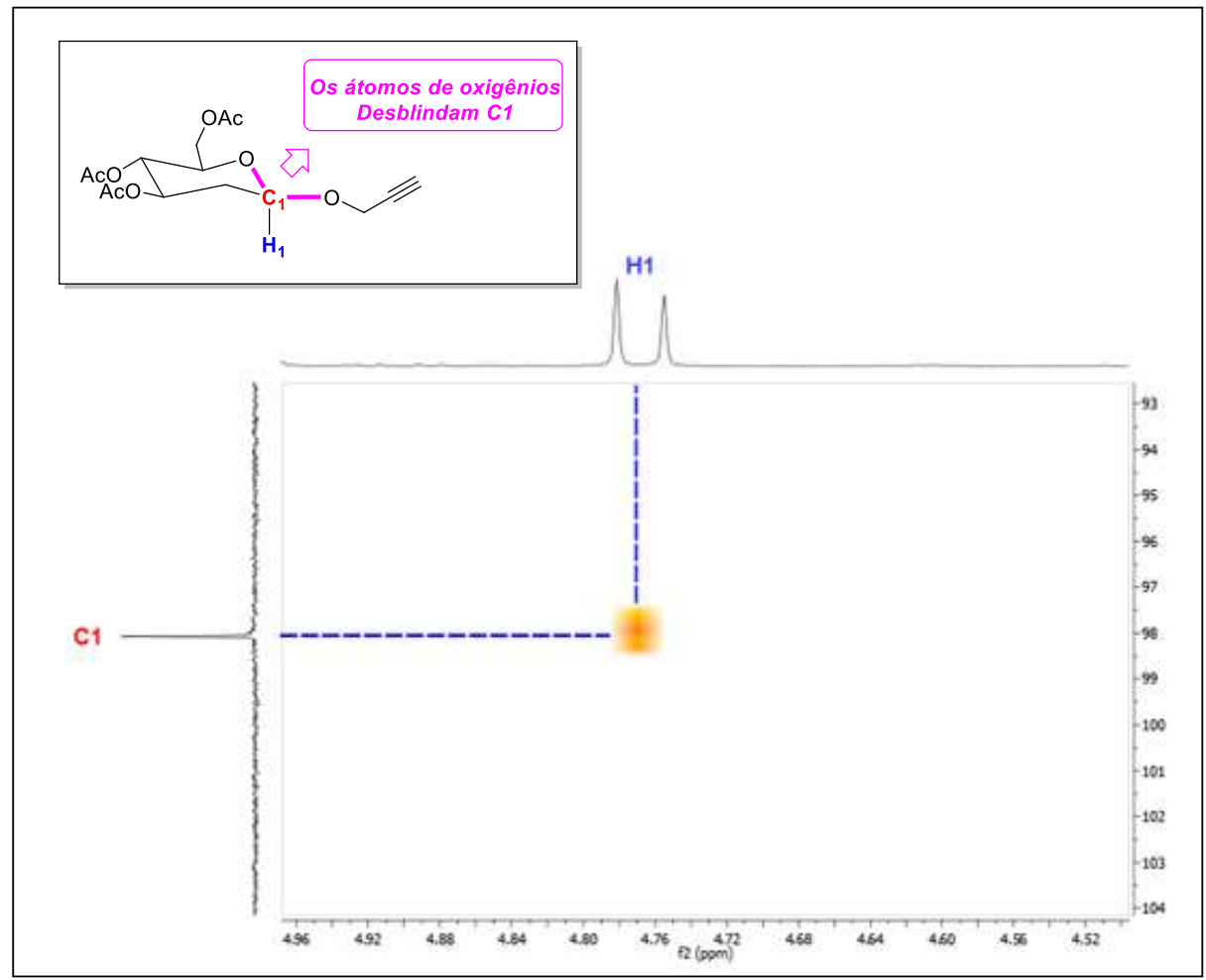

Figura 8: Atribuição de C1 pelo espectro de $\mathrm{HSQC}^{1} \mathrm{H}_{-}{ }^{13} \mathrm{C}$ do composto 3.

Não foi possível realizar a atribuição dos sinais em $\delta_{C} 78,1$ e $75,4 \mathrm{ppm}$, pois estes não apresentaram qualquer correlação no espectro de HSQC. Dessa forma, foi realizado um experimento de correlação heteronuclear de múltiplas ligações (HMBC), onde é observado a correlação entre átomos de carbono e hidrogênio a duas ou três ligações de distância.

Pelo espectro de HMBC, figura 9, é possível verificar que os dois sinais ( $\delta_{C} 78,1$ e 75,4 ppm) se correlacionam com os hidrogênios metilenos $\mathrm{H} 7$, e sendo assim, estes sinais correspondem aos carbonos acetilênicos C8 e C9. Além disso, a correlação do sinal $\delta_{C} 78,1 \mathrm{ppm}$ com o $\delta_{H} 3,71 \mathrm{ppm}$ (H5) permite apontar que este sinal $\left(\delta_{C} 78,1 \mathrm{ppm}\right)$ refere-se a $\mathrm{C} 8$ e o sinal em $\delta_{C} 75,4 \mathrm{ppm}$ corresponde ao C9. Isso é corroborado pelas intensidades dos sinais. O C8 é um carbono quaternário, e dessa forma, apresenta um maior tempo de relaxação e menor NOE (Efeito Nuclear Overhauser), o que resulta na diminuição da sua intensidade [42]. 


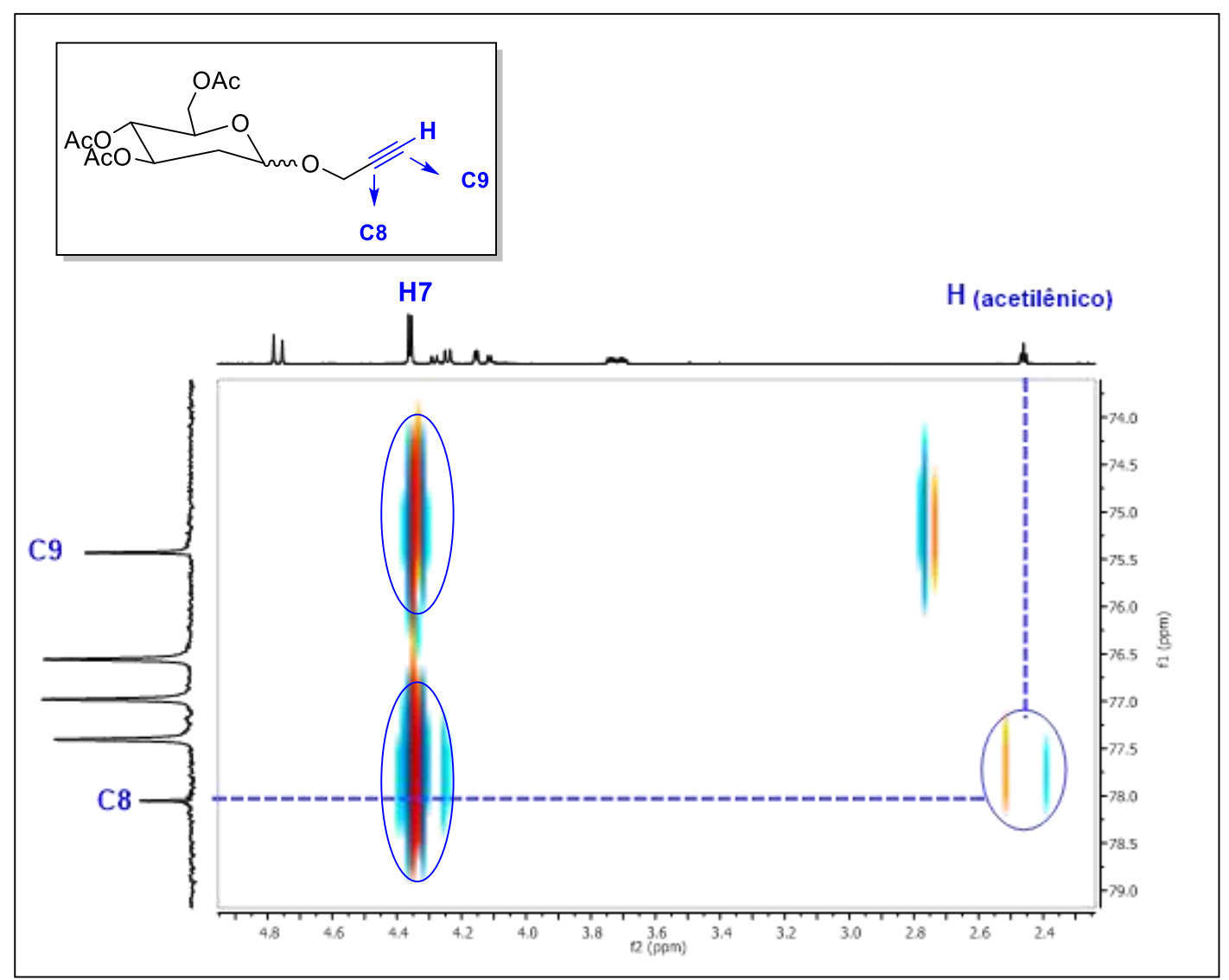

Figura 9. Espectro de $\mathrm{HMBC}{ }^{1} \mathrm{H}_{-}{ }^{13} \mathrm{C}$ do composto 3. Atribuição dos carbonos acetilênicos C8 e C9.

O próximo passo foi averiguar a configuração do hidrogênio ligado ao carbono anomérico afim de determinar qual dos anômeros ( $\beta$ ou $\alpha$ ) foi obtido majoritariamente. Para tanto foi realizado um experimento de NOESY (Espectroscopia de Efeito Nuclear Overhauser). No anômero $\beta$, o hidrogênio H1 está na posição axial e deve apresentar efeito nuclear Overhauser positivo com H5 em função da proximidade espacial, enquanto que no anômero $\alpha$, o hidrogênio H1 está na posição equatorial e não apresentaria (Figura 10).

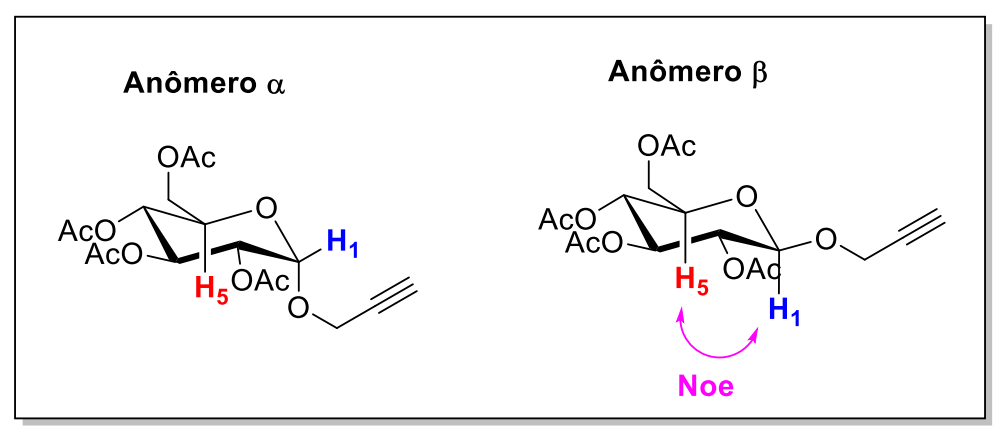

Figura 10. Estrutura dos anômeros $\alpha$ e $\beta$.

Dessa maneira, através do experimento NOESY, o sinal em $\delta_{H} 4,77 \mathrm{ppm}$, referente ao hidrogênio anomérico $\mathrm{H} 1$, foi irradiado seletivamente e foi observado um efeito NOE positivo no sinal centrado em $\delta_{H} 3,72 \mathrm{ppm}$ que corresponde ao hidrogênio H5 (Figura 11). A partir deste resultado, conclui-se que o anômero $\beta$ é o glicosídeo majoritariamente obtido através da reação de glicosilação tipo Fischer. 


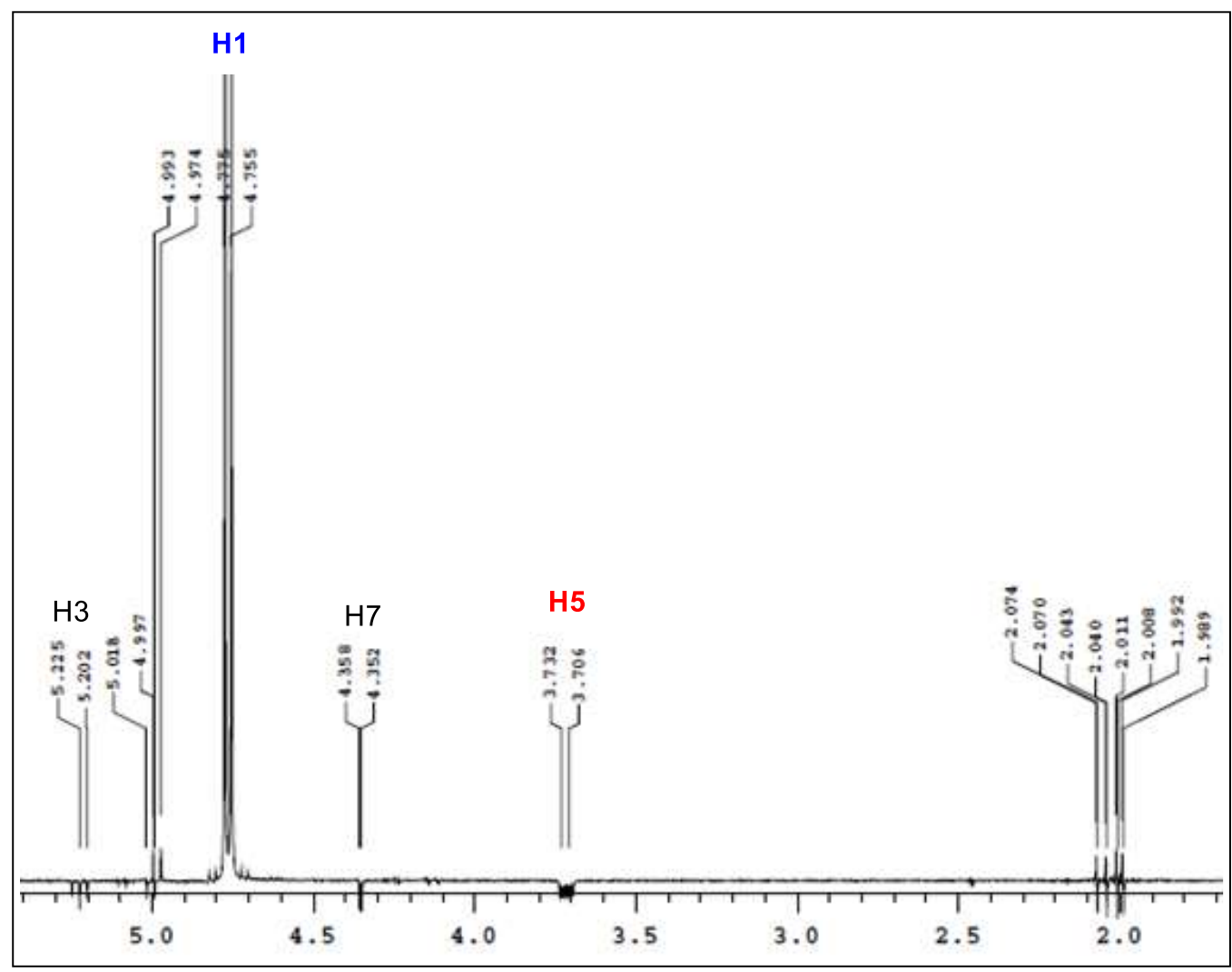

Figura 11: Espectro de NOESY do composto 3 - irradiação do sinal em 4,77 ppm (H1).

Uma vez realizado a síntese e o assinalamento completo do 2-propin-1-il 2,3,4,6-tetra- $O$-acetil$\beta$-D-glicopiranose (3), um estudo das propriedades farmacocinéticas, bioativas e toxicológicas desse composto foi desenvolvido através de uma abordagem in silico. Parâmetros físico-químicos como lipofilicidade, solubilidade e permeabilidade são algumas das características que influenciam a biodisponibilidade oral de candidatos a fármacos [43, 44, 45]. A biodisponibilidade oral, uma das principais propriedades farmacocinéticas, expressa a fração do medicamento que é absorvido pela circulação sistêmica [46, 47]. Em muitos casos, os medicamentos administrados por via oral são metabolizados e eliminados antes de atingir o local da ação terapêutica, diminuindo sua eficácia [48]. Dessa forma, foi utilizado o programa Molinspiration Online Property Calculation para calcular várias propriedades moleculares do composto 3 como área da Superfície polar topológica (TPSA), coeficiente de partição (cLogP), peso molecular (MM), doadores (nDLH) e aceitadores (nALH) de ligação de hidrogênio. Os resultados estão sumarizados na Tabela 1.

Tabela 1 - Predição do perfil farmacocinético e escore bioativo do composto 3.

\begin{tabular}{c|c|c|c|c|c|c}
\hline Composto & TPSA & CLogP & MM & nDLH & AALH & \%ABS \\
\hline \multirow{3}{*}{ OAC $_{\text {OAC }}$} & 123,69 & 0,51 & 386,35 & 0 & 10 & $66,3 \%$ \\
\cline { 2 - 8 } & GPCR & ICM & KI & NRL & PI & EI \\
\cline { 2 - 8 } & 0,16 & $-0,03$ & $-0,20$ & $-0,13$ & 0,06 & 0,32 \\
\hline
\end{tabular}

Segundo Lipinski et al. (1997) [34], um candidato a fármaco não deve violar mais de um dos seguintes critérios: a) número máximo de cinco grupos doadores de ligação hidrogênio; b) número máximo de dez grupos aceptores de ligação hidrogênio; c) apresentar massa molecular menor do que 500 Daltons; e d) coeficiente de partição menor que 5. Essas regras auxiliam nas decisões relacionadas às modificações estruturais e, assim, o número de compostos preparados com propriedades físico-químicas indesejáveis são reduzidos [49].

Os dados apresentados na tabela 1 demonstram que o composto 3 possui boa absorção e permeação, e dessa forma, boa biodisponibilidade oral, visto que todas as propriedades físico- 
químicas calculadas estão de acordo com a Regra dos 5 de Lipinski. A absorção oral prevista para o composto 3 foi de 66,3\%, calculada através da equação \%ABS= 109 - (0.345 x TPSA).

$\mathrm{O}$ rastreamento do composto $\mathbf{3}$ frente aos mais importantes alvos moleculares, a saber, ligante de receptores acoplados a proteína-G (GPCR), modulador de canal iônico (ICM), inibidor de quinase (KI), ligante de receptor nuclear (NRL), inibidor de protease e inibidor de enzima (EI), também foram calculados pelo Molinspiration Online Property Calculation. Uma molécula com escores de bioatividade maior que 0,0 provavelmente são ativas, enquanto que valores entre $-0,5$ a 0,0 devem apresentar atividade moderada e para valores menores que $-0,50$, considera-se inativo [43]. Os resultados apresentados na tabela 1 revelam que o composto 3 exibiu atividade em relação aos alvos moleculares GPCR, PI e EI, e moderada interação com os alvos ICM, KI e NRL.

A toxicidade é uma medida do grau que uma substância pode danificar um organismo ou subestruturas do organismo. Uma das principais razões que causa falha no desenvolvimento de um medicamento é a identificação, em estágio avançado do estudo, da toxicidade in vivo do candidato a fármaco [50]. Nesse sentido, o programa Osiris Property Explorer foi utilizado com o intuído de identificar qualquer característica toxica indesejável do composto 3 (Tabela2).

Tabela 2 - Predição da toxicidade do composto 3.

\begin{tabular}{c|c|c|c|c}
\hline Composto & Mutagênico & Tumorigênico & Irritante & $\begin{array}{c}\text { Efeito } \\
\text { Reprodutivo }\end{array}$ \\
\hline OAc & $\begin{array}{c}\text { Não } \\
\text { observado }\end{array}$ & $\begin{array}{c}\text { Não } \\
\text { Observado }\end{array}$ & $\begin{array}{c}\text { Não } \\
\text { observado }\end{array}$ & $\begin{array}{c}\text { Não } \\
\text { observado }\end{array}$ \\
\hline
\end{tabular}

De acordo com a tabela 2, os resultados da predição da toxicidade indicaram que o composto 3 é seguro em relação a mutagenicidade, tomorigenissidade, irritação e efeito ao sistema reprodutivo, demonstrando, a princípio, que o composto $\mathbf{3}$ apresenta baixa toxicidade. Cabe salientar que a toxicidade prevista pela abordagem in sílico não garante que o composto 3 esteja completamente livre de qualquer efeito toxico ao organismo vivo. No entanto, reforça o perfil promissor desse composto para investigações experimentais futuras.

\section{CONCLUSÃO}

O 2-propin-1-il 2,3,4,6-tetra- $O$-acetil- $\beta$-D-glicopiranose foi obtido em bom rendimento e excelente estereosseletividade. A partir dos experimentos de RMN unidimensional (1D) e bidimensional (2D) foi realizado o assinalamento completo e identificação do anômero $\beta$ como produto majoritário da reação de glicosilação. $\mathrm{O}$ estudo in silico do perfil farmacodinâmico, bioativo e de toxicidade demonstraram que o 2-propin-1-il 2,3,4,6-tetra- $O$-acetil- $\beta$-D-glicopiranose exibe boa biodisponibilidade oral, interage com os principais alvos biológicos e apresenta baixa toxicidade, que fazem deste, um composto com propriedades biológicas promissoras.

\section{AGRADECIMENTOS}

Os autores agradecem às agências de fomento CNPq, FACEPE e CAPES.

\section{REFERÊNCIAS BIBLIOGRÁFICAS}

1. Guan L, Yang H, Cai Y, Sun L, Di P, Li W, Tang Y. ADMET-score - a comprehensive scoring function for evaluation of chemical drug-likeness. Med Chem Comm. 2018 Nov;10(1):148-157, doi: $10.1039 / \mathrm{c} 8 \mathrm{md} 00472 \mathrm{~b}$

2. Mohs RC, Greig NH. Drug discovery and development: role of basic biological research. Alzheimers Dement (NY). 2017 Nov;3(4):651-657, doi:10.1016/j.trci.2017.10.005

3. Hughes J, Rees S, Kalindjian S, Philpott K. Principles of early drug discovery. Br J Pharmacol. 2011 Mar;162(6):1239-1249, doi: 10.1111/j.1476-5381.2010.01127.x 
4. Guido RVC, Andricopulo AD, Oliva G. Planejamento de fármacos, biotecnologia e química medicinal: aplicações em doenças infecciosas. Estud Av. 2010 24(70):81-98, doi: 10.1590/s010340142010000300006

5. Cheng F, Li W, Zhou Y, Shen J, Wu Z, Liu G, Tang Y. admetSAR: A comprehensive source and free tool for assessment of chemical ADMET properties. J Chem Inf Model. 2012 Oct;52(11):3099-3105, doi: $10.1021 / \mathrm{ci} 300367 \mathrm{a}$

6. Van Norman GA. Phase II trials in drug development and adaptive trial design. JACC Basic Transl Sci. 2019 Jun;4(3):428-437, doi: 10.1016/j.jacbts.2019.02.005

7. Fogel DB. Factors associated with clinical trials that fail and opportunities for improving the likelihood of success: a review. Contemp Cli Trials Commun. 2018 Sep;11:156-164, doi: 10.1016/j.conctc.2018.08.001

8. Khan T, Ahmad R, Azad I, Raza S, Joshi S, Khan AR. Computer-aided drug design and virtual screening of targeted combinatorial libraries of mixed-ligand transition metal complexes of 2-butanone thiosemicarbazone. Comput Biol Chem. 2018 Mai;75:178-195, doi: 10.1016/j.compbiolchem.2018.05.008

9. Samizadeh M, Minaei-Bidgoli B. Drug-target interaction prediction by metapath2vec node embedding in heterogeneous network of interactions. Int J Artif Intell Tools. 2020 Feb;29(01): 1-19, doi: $10.1142 / \mathrm{s} 0218213020500013$

10. Kumar R, Harilal S, Gupta SV, Jose J, Thomas DG, Uddin MS, Mathew B. Exploring the new horizons of drug repurposing: A vital tool for turning hard work into smart work. Eur J Med Chem. 2019 Nov;182:1-17, doi: 10.1016/j.ejmech.2019.111602

11. Lin X, Li X, Lin, X. A Review on applications of computational methods in drug screening and design. Molecules. 2020 Mar;25(6):1375-1391, doi: 10.3390/molecules25061375

12. Sliwoski G, Kothiwale S, Meiler J, Lowe EW. Computational Methods in Drug Discovery. Pharmacol Rev. 2013 Jan;66(1):334-395, doi: 10.1124/pr.112.007336

13. Boruah L, Das A, Nainwal LM, Agarwal, N, Shankar, B. In-silico drug design: a revolutionary approach to change the concept of current drug discovery process. Indian J Pharm Biol Res. 2013 Jun;1(2):60-73, doi: 10.30750/ijpbr.1.2.11

14. Mohamed MA, Dirar AI, Hamdoun S. Discovery of two diacetylene glycosides as human uridine-cytidine kinase 2 inhibitors: an in silico approach. J Appl Pharm Sci. 2016 Nov;6(11):034-039, doi: 10.7324/JAPS.2016.601106

15. Hewitt MC, Seeberger PH. Automated solid-phase synthesis of a branched Leishmania Cap terasaccharide. Org. Lett. 2001 Nov;3(23):3699-3702, doi: 10.1021/ol016631v

16. Lionta E, Spyrou G, Vassilatis D, Cournia Z. Structure-Based Virtual Screening for Drug Discovery: Principles, Applications and Recent Advances. Curr Top Med Chem. 2014 Ago;14(16):1923-1938, doi: $10.2174 / 1568026614666140929124445$

17. Ekins S, Mestres J, Testa B. In silicopharmacology for drug discovery: methods for virtual ligand screening and profiling. Br J Pharcol. 2007 Set;152(1):9-20, doi: 10.1038/sj.bjp.0707305

18. Huang W-J, Niu H-S, Lin, M-H, Cheng J-T, Hsu F-L. Antihyperglycemic effect of catalpol in streptozotocin-induced diabetic rats. J. Nat. Prod. 2010 Jun;73(6):1170-1172. doi: 10.1021/np9008317.

19. Brahimi FT, Belkadi M, Othman AA. Synthesis of nonionic surfactants with azole ring bearing Nglycosides and their antibacterial activity. Arab J Chem. 2013 Jun;10:1690-1698, doi: 10.1016/j.arabjc.2013.06.016

20. Chung L-M, Kim Y-O, Ali M, Kim S-H, Park I, Kim E-H, Yang Y-S, Park H-R, Son E-S, Ahmad A. Triterpene glycosides from red ginseng marc and their anti-inflammatory activities. Bioorg Med Chem Lett. 2014 Sep;24(17):4203-4208, doi: 10.1016/j.bmcl.2014.07.042

21.Lv J-J, Yu S, Xin Y, Cheng RR, Zhu H-T, Wang, D, Yang C-R, Xu M, Zhang Y-J. Anti-viral and cytotoxic norbisabolane sesquiterpenoid glycosides from Phyllanthus emblica and their absolute configurations. Phytochemistry. 2015 Jun;117:123-134, doi: 10.1016/j.phytochem.2015.06.001

22. Romero-Ramírez L, García-Álvarez I, Casas J, Barreda-Manso MA, Yanguas-Casás N, Nieto-Sampedro M, Fernández-Mayoralas A. New oleyl glycoside as anti-cancer agent that targets on neutral sphingomyelinase. Biochem Pharmacol. 2015 Set;97(2):158-172, doi: 10.1016/j.bcp.2015.07.009

23. Prassas, I.; Diamandis, E. P. Novel therapeutic applications of cardiac glycosides. Nat Rev Drug Discovery. 2008 Nov;7: 926-935, doi: 10.1038/nrd2682

24. Hu X-Y, Qin F-Y, Lu X-F, Zhang L-S, Cheng Y-X. Three new polyynes from Codonopsis pilosula and their activities on lipid metabolism. Molecules. 2018 Apr;23(4):1-8, doi: 10.3390/molecules23040887

25. Chung C-Y, Yang W-C, Liang C-L, Liu H-Y, Lai S-K, Chang CL-T. Cytopiloyne, a polyacetylenic glucoside from Bidens pilosa, acts as a novel anticandidal agent via regulation of macrophages. $\mathrm{J}$ Ethnopharmacol. 2016 May;184:72-80, doi: 10.1016/j.jep.2016.02.036 
26. Zhou Y, Du D, Liu S, Zhao M, Yuan Y, Li L, Liu J. Polyacetylene glycoside attenuates ischemic kidney injury by co-inhibiting inflammation, mitochondria dysfunction and lipotoxicity. Life Sci. 2018 Jul;204;55-64, doi: 10.1016/j.lfs.2018.05.009

27. Thompson SK, Hoye TR. Molecular structure assignment simplified. Nature. 2017 Jul;547:410-411.

28. Rodrigues RP, Mantoani SP, De Almeida JR, Pinsetta FR, Semighini EP, Da Silva VB, Da Silva CHP. Estratégias de triagem virtual no planejamento de fármacos. Rev Virtual Quim. 2012 Dez;4(6):739-776, doi: $10.5935 / 1984-6835.20120055$

29. Pereira CF, Pasquini C. Espectroscopia de correlação bidimensional: Fundamentos, aplicações e perspectivas. Quim. Nova. 2006 Jan;29(1):143-148, doi: 10.1590/S0100-40422006000100025

30. Elyashberg M. Identification and structure elucidation by NMR spectroscopy. TrAC-Trends Anal Chem. 2015 Jun;69:88-97, doi: 10.1016/j.trac.2015.02.014

31. Forezi LSM, Castelo-Branco FS. Editando espectros de RMN com o software MestReNova: um guia prático. Rev Virtual Quim. 2017 Nov;9(6):2650-2672. doi: 10.21577/1984-6835.20170155

32. Armarego WLF. Purification of Laboratory Chemicals. Amsterdam: Butterworth Heinemann; 2017. 608 p.

33. Mereyala HB, Gurrala SR. A highly diastereoselective, practical synthesis of allyl, propargyl 2,3,4,6tetra- $O$-acetyl- $\beta$-D-gluco, $\beta$-D-galactopyranosides and allyl, propargyl heptaacetyl- $\beta$-D-lactosides. Carbohydr Res. 1998 Nov;307:351-354, doi: 10.1016/s0008-6215(97)10104-5

34. Lipinski CA, Lombardo F, Dominy BW, Feeney PJ. Experimental and computational approaches to estimate solubility and permeability in drug discovery and development settings. Adv Drug Del Rev. 1997; 23(1):4-25, doi: 10.1016/S0169-409X(96)00423-1

35. Fischer, E. H. Ueber die glucoside der alkohole. Ber Dtsch Chem Ges. 1893 Oct;26:2400-2412, doi: $10.1002 /$ cber. 18930260327

36. Narayanaperumal S, Silva RC, Monteiro JL, Corrêa AG, Paixão MW. Iron(III) chloride catalyzed glycosylation of peracylated sugars with allyl/alkynyl alcohols. J Braz Chem Soc. 2012 Nov;23(11);19821988, doi: 10.1590/s0103-50532012005000070

37. Spell M, Wang X, Wahba AE, Conner E, Ragains J. An $\alpha$-selective, visible light photocatalytic glycosylation of alcohols with selenoglycosides. Carbohydr Res. 2013 Mar;369:42-47, doi: 10.1016/j.carres.2013.01.004

38. Quayle P, Rasheed O, Lawrence A, Bailey PA. Modular approach to functionalised dyes. Synlett. 2015 Dez;27(06):905-911, doi:10.1055/s-0035-1561269

39. Rajaganesh R, Ravinder P, Subramanian V, Mohan Das T. FACE-selective fluorogenic cycloaddition reaction between coumarin azides and sugar terminal alkynes: an experimental and computational study. Carbohydr Res. 2011 Ago;346(15):2327-2336, doi: 10.1016/j.carres.2011.07.024

40. Nigudkar SS, Demchenko AV. Stereocontrolled 1,2-cis glycosylation as the driving force of progress in synthetic carbohydrate chemistry. Chem. Sci. 2015 Mar;6:2687-2704, doi: 10.1039/c5sc00280j

41. Silverstein RM, Webster FX, Kiemle DJ, Bryce DL. Identification of organic compounds. New York: College of Environmental Sciense and Forestry; 2005. 140 p.

42. Pavia DL, Lampmam GM, Kriz GS, Vyvyan JR. Introdução á espectroscopia. São Paulo: Cengage Learning. 2010. 230 p.

43. Bhati S, Kaushik V, Singh J. In silico identification of piperazine linked thiohydantoin derivatives as novel androgen antagonist in prostate cancer treatment. Int J Pept Res Ther. 2018 Jul;25:845-860, doi: 10.1007/s10989-018-9734-5

44. Chagas CM, Moss S, Alisaraie L. Drug metabolites and their effects on the development of adverse reactions: revisiting Lipinski's rule of five. Int J Pharm. 2018 Oct;549(1-2):133-149, doi: 10.1016/j.ijpharm.2018.07.046

45. Chen X, Li H, Tian L, Li Q, Luo J, Zhang Y. Analysis of the Physicochemical Properties of Acaricides Based on Lipinski's Rule of Five. J Comput Biol. 2020 Feb, doi: 10.1089/cmb.2019.0323

46. Hetal T, Bindesh P, Sneha, T. A review on techniques for oral bioavailability enhancement of drugs. Int J Pharm Sci Rev Res. 2010 Oct;4(3):203-223.

47. Fasinu P, Pillay V, Ndesendo VMK, Du Toit LC, Choonara YE. Diverse approaches for the enhancement of oral drug bioavailability. Biopharm Drug Dispos. 2011 Apr;32(4):185-209, doi: 10.1002/bdd.750

48. Kim MT, Sedykh A, Chakravarti SK, Saiakhov RD, Zhu H. Critical evaluation of human oral bioavailability for pharmaceutical drugs by using various cheminformatics approaches. Pharm Res. 2013 Apr;31(4):1002-1014, doi: 10.1007/s11095-013-1222-1

49. Santos VLA, Gonsalves AA, Araújo CRM. Abordagem didática para o desenvolvimento de moléculas bioativas: regras dos cinco de Lipinski e preparação de heterocíclicos 1,3,4-oxadiazol em fornos de microondas. Quim Nova. 2018 Jan;41(1):110-115, doi: 10.21577/0100-4042.20170135

50. Pradeepkiran J, Reddy P. Structure based design and molecular docking studies for phosphorylated tau inhibitors in alzheimer's disease. Cells. 2019 Mar;8(3);1-26, doi: 10.3390/cells8030260 